\title{
A standardised neurosurgical referral letter for the inter-hospital transfer of head injured patients
}

\author{
J Keaney, M O Fitzpatrick, D Beard, D A W Ritchie, L T Dunn
}

Accident and

Emergency

Department, Victoria

Infirmary, South

Glasgow University

Hospitals NHST,

Glasgow

J Keaney

D A W Ritchie

Institute of

Neurological Sciences,

Southern General

Hospital, South

Glasgow University

Hospitals NHST

M O Fitzpatrick

L T Dunn

Scottish Trauma Audit Group, Royal

Infirmary of

Edinburgh, Lothian

University Hospitals

NHST, Edinburgh

EH3 9YW

D Beard

Correspondence to:

Diana Beard

(dbeard@staghq.com)

Accepted for publication

8 December 1999

\begin{abstract}
Objectives-(1) To evaluate the use of a standardised neurosurgical referral letter in terms of compliance, completeness and clinical relevance. (2)To compare the clinical information provided on the standardised neurosurgical letter with that provided by referring hospitals that used alternative documentation.

Design-A six month prospective audit was conducted in south west Scotland. Consultant neurosurgeons were asked to weight key clinical variables on the neurosurgical referral letter (NRL). Postal surveys of 114 referring accident and emergency (A\&E) staff and 18 neurosurgical receiving staff were undertaken to determine the clinical relevance of the NRL. Case notes were examined for the presence and level of completeness of the NRL. In the absence of the NRL, a form was completed retrospectively using data from the referring hospital's letter. This enabled comparison of the NRL with routine hospital letters in terms of the availability of key clinical information.

Results-139 adult patients were identified as suitable for inclusion: 99 patients were transferred from 11 hospitals with access to the NRL. The compliance rate for use of the NRLwas $\mathbf{8 2} \%$. Forty patients were transferred from nine hospitals that did not have access to the NRL. The completion rate of key variables on the NRL was higher than when an ordinary letter was sent: $87 \%$ compared with $38 \%$. The NRL was considered useful by 67 of 71 (94\%) A\&E questionnaire respondents and by 14 of 15 neurosurgeons who responded.
\end{abstract}

Conclusions-The widespread acceptance of the NRL and its ability to provide essential clinical information in a concise format not available in routine hospital letters indicates that national, standardised documentation can be implemented if users are involved in both its design and implementation.

(F Accid Emerg Med 2000;17:257-260)

head injury; audit; transfer

Head injury is a common reason for attendance at accident and emergency (A\&E) departments. In the United Kingdom, the vast majority of these patients will be treated without the direct involvement of neurosurgeons. It is estimated that only $3-5 \%$ of all patients with head injury are transferred for neurosurgical care. ${ }^{1}$
This group contains the most severely injured patients. The transfer of head injured patients between hospitals is an everyday occurrence in neurosurgical practice, however, it is an activity that is associated with additional risk. ${ }^{23}$ The difficulties associated with the transfer process are well recognised although most reports have focused on secondary insults such as hypoxia, hypotension, and raised intracranial pressure. ${ }^{4}$ It is recognised that good communication between the referring hospital and the receiving neurosurgical centre is essential if potential problems are to be avoided. $^{5}$

The Scottish Trauma Audit Group (STAG) was established in 1991 with the aim of improving the management of seriously injured patients in Scotland. ${ }^{6}$ In 1994, this national audit established regional multispecialty groups whose remit was to consider issues related to trauma management in their geographical area. An initial analysis identified multiply injured patients whose management was reviewed. The peer review process revealed serious deficiencies in the documentation accompanying patients transferred to the regional neurosurgical unit in South West Scotland. The availability of sequential physiological observations and evidence of exclusion of extra-cranial injuries was variable.

In an attempt to overcome this problem, the decision was taken to rationalise the referral documentation used by the 11 hospitals in South West Scotland that contributed to STAG for the duration of the study. Participation in STAG was dependent on the provision of funding by individual Health Boards. A standardised neurosurgical letter (NRL) was designed to be completed by the A\&E staff (fig 1). The purpose of the NRL was to act as an aide memoire for the referring clinician to ensure that all of the relevant information was available before discussing the case with the neurosurgeon. In addition, the NRL standardised documentation throughout the region and provided a simple method of recording important clinical information from the time of admission to the $\mathrm{A} \& \mathrm{E}$ department to the time of transfer to the neurosurgical unit. Agreement was reached between the participating hospitals and the NRL was introduced in 1995. The aim of this study is to evaluate the use of the NRL in the inter-hospital transfer of head injured patients.

\section{Methods}

All patients with a head injury transferred from $\mathrm{A} \& \mathrm{E}$ departments to the neurosurgical centre were included in this six month prospective study. Children (under 13 years) and patients 
Name:

Address:

DOB: $\square \square \square \square \square \square$

Date of Incident: $\square \square \square \square \square \square$

Time of Incident: $\square \square: \square \square \quad$ Time of Admission:

History:

Physiological Observations

\begin{tabular}{|c|c|c|c|c|c|c|c|c|c|c|c|c|}
\hline & \multirow[t]{2}{*}{ Time } & \multirow[t]{2}{*}{ HR } & \multirow[t]{2}{*}{$\mathrm{BP}$} & \multirow[t]{2}{*}{$\mathrm{RR}$} & \multirow[t]{2}{*}{$\mathrm{O}_{2}$ sat } & \multicolumn{3}{|c|}{ GCS } & \multicolumn{2}{|c|}{ Right Pupil } & \multicolumn{2}{|c|}{ Left Pupil } \\
\hline & & & & & & eye & motor & verbal & reacts & size & reacts & size \\
\hline on arrival & & & & & & & & & & & & \\
\hline on transfer & & & & & & & & & & & & \\
\hline
\end{tabular}

Cranial Injuries:

Extra-Cranial Injuries: (proven or suspected)

C-spine:

Pelvis:

Thoracolumbar:

Limbs:

Other: (specify)

Past Medical History:

Current Medication:

\begin{tabular}{llllll}
\hline Interventions & & & & & \\
& & & & \\
Airway: & Guedel & $\square$ & ETT $\square$ & Other $\square$ & None $\square$ \\
Ventilation: & Spontaneous $\square$ & IPPV $\square$ & \\
Nasogastric tube: & Yes & $\square$ & No $\square$ & \\
Urinary catheter: & Yes & $\square$ & No $\square$ & Urinalysis: \\
\hline
\end{tabular}

\begin{tabular}{|l|l|l|}
\hline Drugs given & Dose & Time \\
\hline Tetanus Toxoid & & \\
\hline & & \\
\hline & & \\
\hline & & \\
\hline
\end{tabular}

\begin{tabular}{|l|l|}
\hline IV Fluids & Volume \\
\hline crystalloid & \\
\hline colloid & \\
\hline blood & \\
\hline & \\
\hline
\end{tabular}

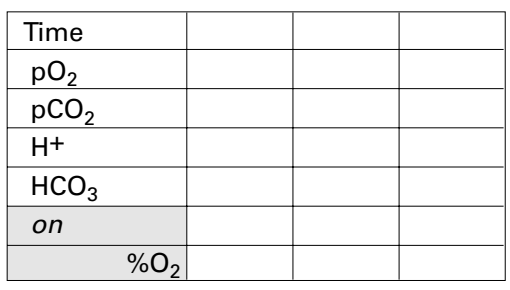

\begin{tabular}{|l|l|l|l|}
\hline Time & & Time & \\
\hline $\mathrm{Hb}$ & & $\mathrm{Na}^{+}$ & \\
\hline WCC & & $\mathrm{K}^{+}$ & \\
\hline Platelets & & $\mathrm{Cl}^{-}$ & \\
\hline Glucose & & $\mathrm{HCO}^{3}$ & \\
\hline X-match & & Urea & \\
\hline & & Creat. & \\
\hline
\end{tabular}

Next of Kin:

Valuables: patient $\square$ relatives $\square \quad$ police $\square$ none $\square$

Tel. No.

Notified: $\quad$ yes $\square$ no $\square$ Clothing: $\quad$ patient $\square$ relatives $\square \quad$ police $\square$ none $\square$

\section{NB: Have you excluded all possible sites of blood loss?}
Transfer with the patient:
Observation charts $\square$
Medical notes $\square$
X-rays $\square$
Signed:
Print: Grade:
Receiving Neurosurgeon:
Grade: Transfer Time: $\square \square: \square \square$

Figure 1 The standardised nueurosurgical referral letter. 
Table 1 Key results of the questionnaire distributed to accident and emergency and neurosurgical medical staff

\begin{tabular}{lll}
\hline & $\begin{array}{l}\text { Aware of the } \\
\text { NRL (\%) }\end{array}$ & $\begin{array}{l}\text { Considered the NRL } \\
\text { relevant (\%) }\end{array}$ \\
\hline A\&E (n=71) & $67(94)$ & $66(93)$ \\
Neurosurgeons (n=15) & $10(68)$ & $14(93)$ \\
\hline
\end{tabular}

with a chronic sub-dural haematoma were excluded. Three outcome measures were examined: clinical relevance, compliance and completeness of key variables. Within this cohort there were two groups of patients; those transferred from hospitals that were members of STAG and that used the NRL and others transferred from non-STAG hospitals that did not have access to the NRL.

Clinical relevance was assessed by means of a structured postal questionnaire sent to $A \& E$ and neurosurgical medical staff. In addition, senior neurosurgeons were asked to identify and rate key clinical variables on the NRL using a scale ranging from "not at all useful" to "always useful". Those variables where consensus was reached ("frequently" or "always" useful) were determined to be the key variables by which completeness of the NRL should be judged and alternative documentation compared.

The case notes of all patients with a head injury admitted to the neurosurgical unit were reviewed. All patients who had been transferred from STAG hospitals should have had the NRL completed. The NRLs were photocopied and checked for completeness of key variables. Cases from STAG hospitals who did not have a completed NRL and those from non-STAG hospitals had a NRL completed retrospectively using the information contained within the letter sent from the referring hospital. Information contained in ambulance records was not included.

\section{Results}

During the six month period examined, 139 patients with a diagnosis of head injury were transferred to the neurosurgical unit. There were 99 patients transferred from STAG hospitals with access to the NRL and 40 patients transferred from non-STAG hospitals that did not have access to the NRL. The NRL had been completed for 81 of the 99 cases transferred from the STAG hospitals giving a compliance rate of $82 \%$.

The response rate to the postal survey undertaken in the $11 \mathrm{~A} \& \mathrm{E}$ departments with access to the NRL was $62 \%$ (71 of 114 ). The majority of non-responders were senior house officers. A similar questionnaire distributed to the neurosurgeons had a response rate of 15 of $18(83 \%)$. The level of awareness of the NRL

Table 2 The availability of key clinical variables determined by senior neurosurgeons to be "frequently" or "always" useful

\begin{tabular}{llllll}
\hline & GCS & $\begin{array}{l}\text { Pupillary } \\
\text { size }\end{array}$ & $\begin{array}{l}\text { Blood } \\
\text { pressure }\end{array}$ & $\begin{array}{l}\text { Oxygen } \\
\text { saturation }\end{array}$ & $\begin{array}{l}\text { Extra-cranial } \\
\text { injuries }\end{array}$ \\
\hline NRL access completed $(\mathrm{n}=81)$ & $75(92.6)$ & $74(91.4)$ & $74(91.4)$ & $57(70.4)$ & $71(87.7)$ \\
NRL access not completed $(\mathrm{n}=18)$ & $9(50.0)$ & $7(38.9)$ & $6(33.3)$ & $2(11.1)$ & $8(44.4)$ \\
Hospital letter $(\mathrm{n}=40)$ & $33(82.5)$ & $17(42.5)$ & $16(40)$ & $7(17.5)$ & $22(21.8)$ \\
\hline
\end{tabular}

Percentages shown in parentheses. among $A \& E$ doctors was $94 \%$ (67 of 71 ). The four A\&E respondents who were not aware of the NRL were all senior house officers who were not responsible for referring patients to the neurosurgical unit. The key results of the questionnaire are given in table 1 . Only 13 clinicians $(22 \%)$ completed the NRL after referring the patient, which indicates that the NRL fulfils its capacity as an aide memoire. The NRL had replaced hospital letters for $63.5 \%$ of respondents. The five neurosurgical respondents who were not aware of the NRL were four consultants (who were not responsible for accepting referrals) and one visiting registrar.

The NRL was considered to be clinically relevant by $93 \%$ of both A\&E and neurosurgical respondents.

The main reasons given for the high rating of usefulness were its concise nature, simple layout and relative ease of completion in the emergency setting. The most common suggestions for improving the NRL related to the need for more space to include the results of investigations such as a clotting screen and computed tomography. The part of the form considered least useful was the section relating to the patient's belongings and next of kin.

Comparison of the completeness of the key variables was made between three groups: those patients with a NRL completed, those where one was available but not used, and those without access to the NRL. The key clinical variables were considered to be the five parameters essential to the referral of a head injured patient. They were: the patient's conscious level as assessed by the Glasgow Coma Scale (GCS), pupillary size and reactivity, mean arterial blood pressure, oxygen saturation and the presence of extra-cranial injuries. The availability of the key clinical variables is illustrated in table 2. GCS was recorded on $93 \%$ of NRLs from STAG hospitals and on $83 \%$ of referral documents from non-STAG units. Only $50 \%$ of cases from STAG hospitals that had failed to complete the NRL had the GCS recorded. Pupillary size and reactivity was noted on $92 \%$ in NRLs compared eith around $40 \%$ for the other groups. The documentation of blood pressure, oxygen saturation and the presence of extra-cranial injuries was similarly low from units that did not use the NRL irrespective of their being members of STAG or not.

\section{Discussion}

Despite being an everyday occurrence, the inter-hospital transfer of patients with severe head injuries is potentially hazardous. Within the past decade the importance of adequate assessment and resuscitation, and the prevention of secondary insults, has become widely accepted. ${ }^{7}$ The need for good communication is recognised as fundamental to the transfer process. The limited availability of electronic communication systems within the National Health Service necessitates effective written communication if patients are not to be placed at risk. ${ }^{5}$ Good communication depends on the referring clinician having the most important information available in an organised manner 
at the time of referral. This is the only way in which a useful discussion can ensue between the specialties involved and thus expedite a safe and efficient transfer.

The audit has demonstrated that the NRL is well accepted in the A\&E departments and the neurosurgical unit. The NRL provides a simple means of recording important clinical information. It also has the advantages of being standardised throughout the region, quick to complete and it serves as an aide memoire for the referring $A \& E$ doctor. These features are of benefit in the emergency setting. Furthermore, there was a marked improvement in the completion rate of the key clinical variables when the NRL was used. In cases where in the NRL was available but not used, the documentation of the key variables was poorer than in those cases where the hospital did not have access to the NRL. The reason for this is not apparent. When the NRL was not used, the quality of the information conveyed to the neurosurgical unit was sub-optimal. The GCS was the most frequently recorded variable regardless of whether or not the NRL was used. Overall, the NRL was superior to any other means of communication such as hospital letter or notes.

STAG is charged with improving the management of injured patients in Scotland. The value of a national audit is that a network exists to implement change and promote multispecialty audit, the benefits of which are well reported. ${ }^{8}$ The value of standardised communication for patient transfer is recognised. ${ }^{9}$ The high level of user acceptability of the NRL is likely to result from the collaborative process of designing the NRL that began with each A\&E department submitting routine documentation for analysis. The consultants representing the various specialties involved in trauma management offered opinions on the design of the document. After further consultation the final document was agreed by the majority of those who would use it and it was introduced throughout the region. Implementation of the standardised NRL was considered successful on the basis of the number of NRLs distributed by STAG and the frequency with which they appeared in the case notes of the neurosurgical patients. Given that it is a requirement of audit to evaluate any change implemented as a result of an identified deficit, this anecdotal evidence required testing by means of a formal audit to evaluate the use of the NRL. This requirement formed the basis for this study.

The NRL has since been introduced throughout Scotland where the majority of the 25 A\&E departments use it for transferring not only patients who have a head injury, but also those who have had a sub-arachnoid haemorrhage. Requests to reproduce the NRL have been received from hospitals in English health authorities and neurosurgical units throughout the UK. The NRL has been included in the Scottish Intercollegiate Guideline Network (SIGN) guidelines on The early management of patients with a head injury. These guidelines should be published in 2000 .

The authors wish to thank the staff of the Scottish accident and emergency departments and the staff of the Institute of Neurological Sciences at the Southern General Hospital in Glasgow for their cooperation with this study.

Funding: none.

Conflicts of interest: none.

Contributors

All authors were involved in the design of the study. The data were collected by John Keaney, Diana Beard and Michael Fitzpatrick. Analysis was performed by Diana Beard and John Keaney. The paper was written by Michael Fitzpatrick and Diana Beard. Laurence Dunn and David Ritchie edited the paper. Laurence Dunn is the guarantor of the paper.

1 Jennett B, MacMillan R. Epidemiology of head injury. BMF 1981;282:101-4.

2 Gentleman D Jennett B. Audit of the transfer of unconscious head-injured patients to a neurosurgical unit. Lancet 1990;335:330-4.

3 Lambert SM, Willet K. Transfer of multiply-injured patients for neurosurgical opinion: a study of the adequacy patients for neurosurgical opinion: a study of the adequacy

4 Dunn LT. Secondary insults during the interhospital transDunn LT. Secondary insults during the interhospital trans-
fer of head-injured patients: an audit of transfers in the fer of head-injured patients: an audit

5 Gentleman D, Dearden M, Midgley S, et al. Guidelines for resuscitation and transfer of patients with serious head injury. $B M \mathcal{F}$ 1993;307:547-52.

6 Little K, Steedman DJ, Beard D. Preliminary analysis of the care of injured patients in five Scottish teaching hospitals: first report from the Scottish Trauma Audit Group (STAG). Health Bull 1995;53:55-65.

7 Advanced Trauma Life Support. Chicago: American College of Surgeons Committee on Trauma, 1997.

8 Crombie IK, Davies HTO, Abraham SCS, et al. The audit handbook: improving healthcare through clinical audit. Chichester: John Wiley, 1993.

9 SIGN: A report on a recommended referral document. Scottish Intercollegiate Guideline Network Report no 31 Edinburgh: Metro Press, 1998. 